\title{
Estimating the productive potential of five natural forest types in northeastern China
}

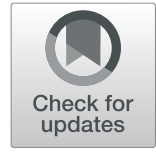

Zhaofei $\mathrm{Wu}^{1}$, Zhonghui Zhang ${ }^{2}$ and Juan Wang ${ }^{1 *}$

\begin{abstract}
Background: There is a serious lack of experience regarding the productive potential of the natural forests in northeastern China, which severely limits the development of sustainable forest management strategies for this most important forest region in China. Accordingly, the objective of this study is to develop a first comprehensive system for estimating the wood production for the five dominant forest types.

Methods: Based on a network of 384 field plots and using the state-space approach, we develop a system of dynamic stand models, for each of the five main forest types. Four models were developed and evaluated, including a base model and three extended models which include the effects of dominant height and climate variables. The four models were fitted, and their predictive strengths were tested, using the "seemingly unrelated regression" (SUR) technique.

Results: All three of the extended models increased the accuracy of the predictions at varying degrees for the five major natural forest types of northeastern China. The inclusion of dominant height and two climate factors (precipitation and temperature) in the base model resulted in the best performance for all the forest types. On average, the root mean square values were reduced by $13.0 \%$ when compared with the base model.

Conclusion: Both dominant height and climate factors were important variables in estimating forest production. This study not only presents a new method for estimating forest production for a large region, but also explains regional differences in the effect of site productivity and climate.
\end{abstract}

Keywords: Forest types, Forest growth, Climate, Site conditions, Seemingly unrelated regression

\section{Background}

Northeastern China, accounting for $37 \%$ of the country's total forest land, is known for its high diversity of forest types (Zheng et al. 2001). The forests of the region provide indispensable ecological functions and are important for regulating the climate of both the Northeastern Plain and the North China Plain. However, there is a serious lack of information regarding the growth and production of the forests in the region, which has limited the application of sustainable forest management practices. The development of scientific forest management strategies is dependent on accurate descriptions of the current state of the forested areas, and also on accurate estimates of future development. Current information on forest types and growing stock volumes can be obtained from forest inventories taken at one point in

\footnotetext{
*Correspondence: claire_wangj@126.com

${ }^{1}$ Research Center of Forest Management Engineering of State Forestry and Grassland Administration, Beijing Forestry University, Beijing 100083, China Full list of author information is available at the end of the article
}

time. Estimates of future development are based on growth and yield models (Gadow and Hui 1999; Burkhart 2008; García et al. 2011; Da Cunha et al. 2016).

Due to improvements in statistical methods and computer applications, the traditional yield tables have gradually been replaced by dynamic growth models (Buckman 1962; Clutter 1963; Mora et al. 2012; Burkhart and Tomé 2012). Modeling the growth and yield of uneven-aged forests has received much less attention than that of even-aged forests (Peng 2000). An early uneven-aged growth and yield model for mixed northern hardwood forests was proposed Moser and Hall (1969), which expressed the yield as a function of time, initial volume, and basal area. Many studies regarding uneven-aged growth and yield have been conducted since (Burkhart and Tomé 2012; Choi and An 2016). For instance, Murphy and Farrar (1982) used the same method as Moser-Hall to develop models for the basal area and volume projection of uneven-aged 
loblolly-shortleaf pine forest stands. Also, Sullivan and Clutter (1972) developed compatible growth and yield models which consisted of a system of equations in to predict both volume and basal area (Clutter 1963).

In China, due to limited data, researchers were more inclined to apply models which could be used to estimate the growth of individual trees (Ren et al. 2008; Zeng et al. 2017). The single-tree growth models were based on the competition relationship between individual trees and their immediate neighbors (Palahí et al. 2008; Zhao 2011). However, the decisions to use treelevel models or stand-level models were dependent on specific objectives (Burkhart and Tomé 2012). The single-tree growth models were only suitable for specific environmental conditions, and the differences in environmental conditions affected the applicability of the models. In addition, it was difficult to estimate the development of an entire forest based on single tree models. Stand growth and production models are required for estimating the development of extensive forest areas. The few existing stand growth models in China were mainly developed for plantations. Unfortunately, these models were often based on limited data sets which tended to limit their applicability (Zang 2016). In addition, the increasing global concerns regarding climate change and ecosystem functions have generated a strong interest in natural forest management strategies (Choi and An 2016). At the present time, there are no unified natural forest stand growth models for the uneven-aged forests of northeastern China. This situation has severely limited the development of sustainable forest management strategies for the region.

Based on a new and extensive set of observations collected in the forests of northeastern China, the objective of this study is to 1) develop dynamic stand models for five main forest types including site and climate variables, and to 2) evaluate the predictive strengths of these models.

\section{Methods}

Study area

A network of 384 circular field plots was established in the temperate natural forests of four northeastern provinces (Inner Mongolia, Liaoning, Jilin, and Heilongjiang) in China. Each sample plot covers an area of 0.1 ha. The plots are located between $39^{\circ} 42^{\prime} 48^{\prime \prime}$ to $53^{\circ} 19^{\prime} 21^{\prime \prime}$ north and $119^{\circ} 48^{\prime} 12^{\prime \prime}$ to $134^{\circ} 01^{\prime} 01^{\prime \prime}$ east. The sampled area includes eight mountains. The geographical distribution is presented in Fig. 1. The average annual temperature ranges from $-5.57{ }^{\circ} \mathrm{C}$ to $9.80^{\circ} \mathrm{C}$, with an average annual precipitation of 363.83 to $1073.72 \mathrm{~mm}$.

\section{Data set}

The data used in this study were collected during the summer of 2017. In order to represent the natural forests in each of the eight mountain areas, the plots were distributed systematically. The distances between the individual plots ranged from 24 to $60 \mathrm{~km}$, depending on the area of the eight mountains. At each pre-determined sample site, a circle with a radius of $17.85 \mathrm{~m}$ was established. A hand-held GPS was used to record the longitude, latitude, and altitude of each of the sites. Trees with a breast height diameter (DBH, measured at $1.3 \mathrm{~m}$ above ground level) of $5 \mathrm{~cm}$ or more were labeled with numbers. For each sample tree, the species, DBH, height, and location (which were determined by the north deviation angle and distance) were recorded.

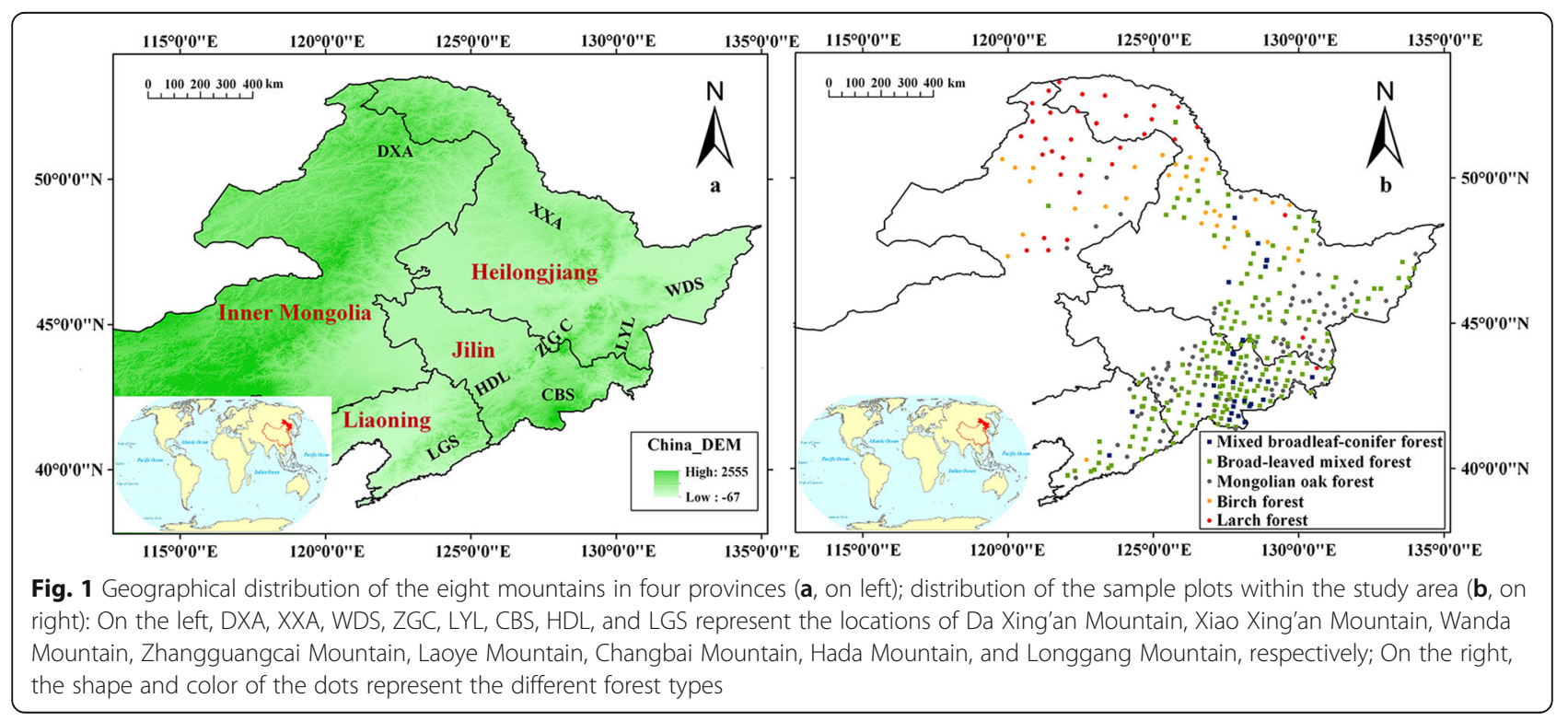


In addition, an increment borer with an auger diameter of $5.15 \mathrm{~mm}$ was utilized to extract an increment core from the north side of each tree at a height of 1.3 $\mathrm{m}$. The increment core of each tree had to pass through the tree center, and its length was required to exceed 2 $\mathrm{cm}$. In order to consider short-term abnormal fluctuations in ring widths which may have been caused by climatic extremes, a five-year mean was adopted, as suggested by Gadow and Hui (1999). The two five-year periods' (2007 to 2012 and 2012 to 2017) radial increments of each tree were recorded to the nearest 0.01 $\mathrm{mm}$. The two five-year periods' diameter increments $\left(i d_{1}, i d_{2}\right)$ were used to reconstruct the 2012 and 2007 diameters at breast height $\left(\mathrm{DBH}_{12}, \mathrm{DBH}_{07}\right)$ by subtracting $i d_{1}$ and $i d_{2}$. Thus, the bark thickness was supposed to be constant during the last 10 years. Also, the breast height ages of $15 \%$ of the tallest trees were assessed using increment cores.

The volume of each sample tree was calculated using the available stem volume equations for different species in the various regions (listed in Additional file 1). In the current study, it was not possible to include the effects of mortality and ingrowth in the estimate. Five stand variables were calculated for each plot as follows: (1) Dominant height $\left(H_{\mathrm{dom}}, \mathrm{m}\right)$ defined as the mean height of the $15 \%$ tallest trees; (2) age $(A)$, defined as the average breast height age of the dominant trees; (3) number of trees per hectare $(N)$; (4) stand basal area $\left(G, \mathrm{~m}^{2} \cdot \mathrm{ha}^{-1}\right)$; and (5) stand volume $\left(V, \mathrm{~m}^{3} \cdot \mathrm{ha}^{-1}\right)$. In addition, the daily values of the mean temperature and total precipitation were obtained for the period ranging from 2007 to 2017 at a $0.5^{\circ}$ latitude-longitude spatial resolution from the KNMI Climate Explorer, which is a research tool used to assess the climate conditions in different regions of the world (https://climexp.knmi.nl). This study also used an Inverse Distance Weighted (IDW) interpolation method in the ArcGIS 10.4.1 software to assign the values to the plot locations. The growth season temperature and precipitation values (GST and GSP) of each survey plot were thus obtained. The frequency distributions of the seven variables used for the model development are presented in Fig. 2.

In order to stratify the observations according to forest type, the 384 plots were classified into five forest types based on the volume proportions of the different tree species in each plot (Table 1, Additional file 2). These types are referred to in this study as follows (the summary statistics are listed in Additional file 3): Broadleaved mixed forest (192 plots); mixed broadleaf-conifer forest (30 plots); Mongolian oak forest (92 plots); larch forest (37 plots); and birch forest (33 plots). The dominant broad-leaved species are Quercus mongolica, Betula platyphylla, Tilia amurensis, Betula davurica, Llmus japonica and Acer mono; the main coniferous species are Pinus koraiensis, Abies nephrolepis and Larix gmelinii.

\section{Stand growth model}

\section{Reference model}

The Sullivan and Clutter (1972) model is a widely used and arguably one of the most logical and effective systems for estimating forest production (see a recent detailed description in Burkhart and Tomé 2012). The system has been used in many studies, and found to give good results (Borders 1989; Zhao 2011; Burkhart and Tomé 2012):

$$
\begin{aligned}
& \ln V_{1}=a_{0}+a_{1} \mathrm{SI}+a_{2} t_{1}^{-1}+a_{3} \ln G_{1} \\
& \ln G_{2}=\left(\frac{t_{1}}{t_{2}}\right) \ln G_{1}+b_{0}\left(1-\frac{t_{1}}{t_{2}}\right)+b_{1} \operatorname{SI}\left(1-\frac{t_{1}}{t_{2}}\right) \\
& \ln V_{2}=\ln V_{1}+c_{0}\left(t_{2}^{-1}-t_{1}^{-1}\right)+c_{1}\left(\ln G_{2}-\ln G_{1}\right)
\end{aligned}
$$

where $a, b$, and $c$ represent the estimated coefficients; SI is the stand site index which characterizes the stand site quality; $t_{1}$ and $t_{2}$ are the ages of the initial and predicted periods, respectively; $V_{1}$ and $V_{2}$ denote the stand volumes of the initial and predicted periods; $G_{1}$ and $G_{2}$ are the basal areas of the initial and predicted periods.

Equation 1 is based on Schumacher's equation describing a static forest, which utilizes the predictions of the current stand volumes from the site index, along with the ages and stand basal areas (Schumacher 1939; Borders 1989; Burkhart and Tomé 2012). Equation 2 can be used to estimate the future basal areas based on the existing stand states. Actually, Eq. 1 can be used for estimating both $V_{1}$ and $V_{2}$. This system was found to be consistent with the logic of forest development:

(1) When $t_{2} \rightarrow t_{1}$, then $\ln G_{2} \rightarrow \ln G_{1}$

(2) When $t_{2} \rightarrow+\infty$, then $\ln G_{2} \rightarrow b_{0}+b_{1}$ SI, which indicates that the future area of the stand will gradually stabilize and conform to the growth trend of the stand;

(3) Therefore, the model will be compliant with the compatibility principle which was previously described by Clutter (1963) and Clutter et al. (1983).

\section{Extended model}

The model in the current study is based on an original model proposed by Sullivan and Clutter (1972). We deleted Eq. 3 of the reference model. In addition, some variables were deleted, others added. Four systems of equations were finally selected for this study, as detailed in Table 2. Each system contained two equations, and the site index (SI) of the original model was deleted resulting in the basic stand production model $\left(\mathrm{M}_{0}\right)$. 


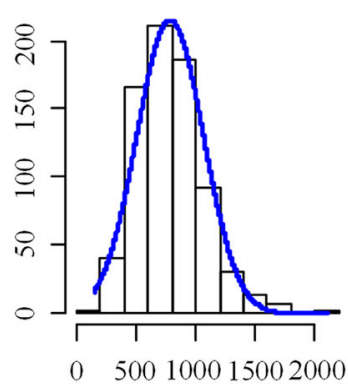

$N$
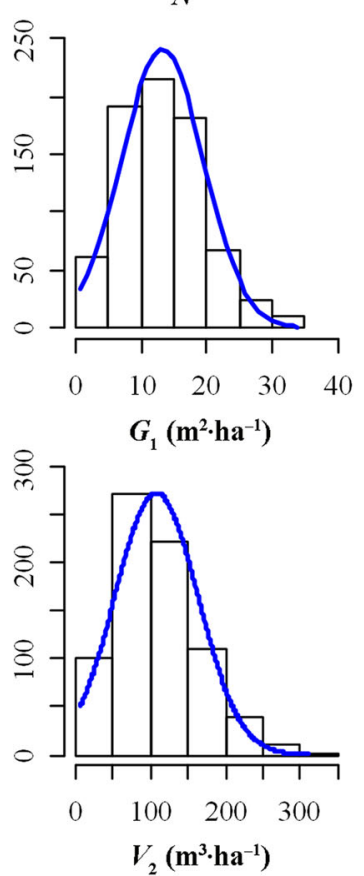
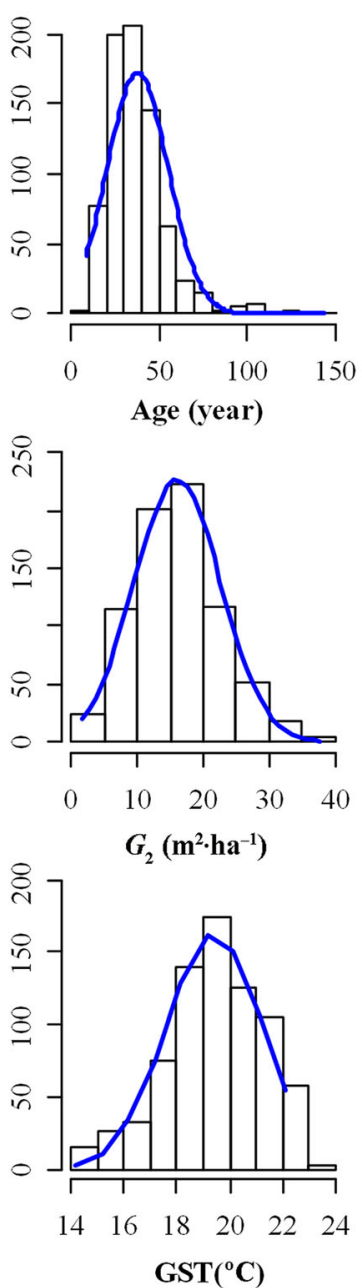
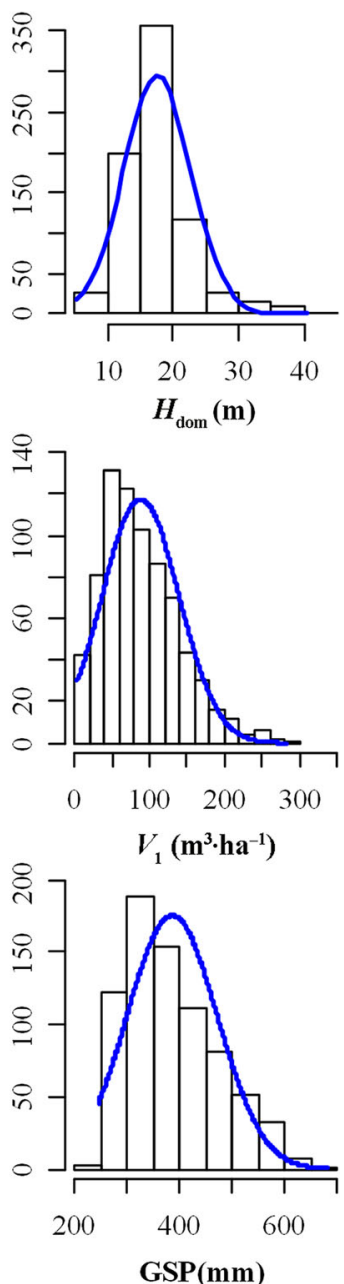

Fig. 2 Frequency distributions of the main variables of the two five-year periods with fitted trend lines: $N$ indicates the number of trees per hectare; Age and $H_{\text {dom }}$ are the average age and height of dominant trees, respectively; $V_{1}$ and $V_{2}$ denote the stand volumes of the initial and final phases of the two five-year periods, respectively; $G_{1}$ and $G_{2}$ are the basal areas of the initial and final phases of the two five-year periods, respectively; and GST and GSP are the mean growth season temperatures and precipitation of the two five-year periods, respectively

Site index, expressed by the average height of the dominant trees at a specific reference age, has become one of the most widely used variables used in forest growth modeling (Clutter et al. 1983; Monserud and Sterba 1996; Skovsgaard and Vanclay 2008; Guo et al. 2012). It appears that there is no general index to reflect the site quality for uneven-aged forests. We decided to select dominant height to reflect the site condition of these natural forests (see Gül et al. 2005; Pinto et al.
2008). Therefore, dominant height was included in the first extended model referred to as $M_{1}$ (Table 2).

Climate variables, such as temperature and precipitation, are known to directly affect the productive potential of forest ecosystems. In addition, climate variables have indirect impacts on forest productivity via species composition and nutrient cycling (Rustad et al. 2012; Ratcliffe et al. 2016; Morin et al. 2018). In the current study, model $\mathrm{M}_{2}$ includes two climate variables added to

Table 1 Classification standard used in China for different forest types

\begin{tabular}{ll}
\hline Forest type & Classification based on volume proportion \\
\hline Pure forest & Single tree species $\geq 65 \%$ of total volume \\
Coniferous mixed forest & Coniferous species $\geq 65 \%$ of total volume \\
Broad-leaved mixed forest & Broad-leaved species $\geq 65 \%$ of total volume \\
Mixed broadleaf-conifer forest & Broad-leaved or conifer species account for $25 \%-65 \%$
\end{tabular}


Table 2 The four systems of equations developed and examined in this study

\begin{tabular}{ll}
\hline Model & Form \\
\hline$\left[M_{0}\right]$ Base Model & $\ln V_{1}=a_{0}+a_{1} t_{1}^{-1}+a_{2} \ln G_{1}$ \\
& $\ln G_{2}=\left(\frac{t_{1}}{t_{2}}\right) \ln G_{1}+b_{0}\left(1-\frac{t_{1}}{t_{2}}\right)$ \\
{$\left[M_{1}\right]$ Base Model with $H_{\text {dom }}$} & $\ln V_{1}=a_{0}+a_{1} H_{\text {dom }}+a_{2} t_{1}^{-1}+a_{3} \ln G_{1}$ \\
& $\ln G_{2}=\left(\frac{t_{1}}{t_{2}}\right) \ln G_{1}+b_{0}\left(1-\frac{t_{1}}{t_{2}}\right)+b_{1} H_{\text {dom }}\left(1-\frac{t_{1}}{t_{2}}\right)$ \\
& $\ln V_{1}=a_{0}+a_{1} t_{1}{ }^{-1}+a_{2} \ln G_{1}$ \\
{$\left[M_{2}\right]$ Base Model with Climate } & $\ln G_{2}=\left(\frac{t_{1}}{t_{2}}\right) \ln G_{1}+b_{0}\left(1-\frac{t_{1}}{t_{2}}\right)+\left(b_{1}\right.$ GST $+b_{2}$ GSP $)\left(1-\frac{t_{1}}{t_{2}}\right)$ \\
& $\ln V_{1}=a_{0}+a_{1} H_{\text {dom }}+a_{2} t_{1}{ }^{-1}+a_{3} \ln G_{1}$ \\
& $\ln G_{2}=\left(\frac{t_{1}}{t_{2}}\right) \ln G_{1}+b_{0}\left(1-\frac{t_{1}}{t_{2}}\right)+\left(b_{1} H_{\text {dom }}+b_{2} G S T+b_{3} G S P\right)\left(1-\frac{t_{1}}{t_{2}}\right)$
\end{tabular}

$a, b$, and $c$ are the estimated coefficients; $H_{\text {dom }}$ indicates the dominant height, $t_{1}$ and $t_{2}$ are the age of the initial and predicted periods, respectively; $V_{1}$ and $V_{2}$ indicate the stand volume of the initial and predicted periods, respectively; $G_{1}$ and $G_{2}$ are the basal area of the initial and predicted periods, respectively. GST and GSP are the growth season temperatures and precipitation

the base model $\left(M_{0}\right)$. Finally, a third extended model $\left(\mathrm{M}_{3}\right)$ uses both dominant height and climate factors. In this study, the average height of the dominant trees $\left(H_{\mathrm{dom}}\right)$ was used while climate was expressed by the average regional temperatures during the growing season $\left(\mathrm{GST},{ }^{\circ} \mathrm{C}\right)$ and the growing season precipitation (GSP, $\mathrm{mm})$.

\section{Parameter estimation and model comparison}

The parameter estimates and fit statistics of the four model systems were evaluated to determine if they were significantly different from zero using an asymptotic ttest (Álvarez-González et al. 2010; Temesgen et al. 2014). The results of the estimates are based on the numerical and graphical analyses of the residuals. During the analysis, three statistical criteria were examined (Table 3): 1) bias $(\bar{E})$, which evaluates systematic deviations of the model from the observations; 2) root mean square error (RMSE), which measures the precision of the estimates and any bias in the equation; and 3) model efficiency (MEF), which indicates the proportion of the total variance explained by the model, adjusted for the number of model parameters and observations.

During model evaluation, we first assess whether there is a significant difference in the deviation of the different models. Subsequently, the model with the largest MEF and lowest RMSE was prioritized based on the smallest difference. Following that, three indices of the different models were evaluated for each forest type. After analyzing the results, the optimum model was selected for each

Table 3 Criteria used to evaluate the performance of the models

\begin{tabular}{lll}
\hline $\bar{E}$ & RMSE & MEF \\
\hline$\frac{\sum_{i=1}^{n}\left(y_{i}-\hat{y}_{i}\right)}{n}$ & $\sqrt{\frac{\sum_{i=1}^{n}\left(y_{i}-\hat{y}_{i}\right)^{2}}{n-p}}$ & $1-\frac{(n-1) \sum_{i=1}^{n}\left(y_{i}-\hat{y}_{i}\right)^{2}}{(n-p) \sum_{i=1}^{n}\left(y_{i}-\bar{y}_{i}\right)^{2}}$ \\
\hline
\end{tabular}

$y_{i}, \hat{y}_{i}$, and $\bar{y}_{i}$ are the observed, predicted, and average values of the dependent variable, respectively; $\mathrm{n}$ is the number of samples used in fitting the function: and $p$ indicates the number of model parameters type of forest. For all 384 plots, broad-leaved mixed forest (192 plots) and Mongolian oak forest (92 plots), 70\% of the samples were used for model development and comparison. Independent samples from the remaining plots were then used for evaluating the optimal model. Due to the restricted number of samples, all plots of the other three forest types (mixed broadleaf-conifer forest (30 plots); larch forest (33 plots); and birch forest (37 plots)) were used to develop the models, and evaluated using bias, RMSE, and MEF. After evaluating the "threestage least squares" (3SLS) technique (Zellner and Theil 1992), we fitted all four models with the "seemingly unrelated regression" (SUR) technique (Zellner 1962). The "systemfit" package within the $R$ programming environment ( $R$ version 3.5.1) was used to implement the method.

\section{Results}

\section{Stand growth}

The data set covers a wide array of stand densities, with the number of trees.ha ${ }^{-1}$ ranging from 150 to 2100; stand volumes ranging from 6.77 to $310.4 \mathrm{~m}^{3} \cdot \mathrm{ha}^{-1}$; and basal areas from 1.60 to $37.69 \mathrm{~m}^{2} \cdot \mathrm{ha}^{-1}$ (Fig. 2). As can be seen in Fig. 3, the plots are sorted by the total volume and basal area which had accumulated in the final phase of the two five-year periods. In the figure, the differences in stand volume increments (VI) and basal area increments (BAI) of each plot are shown by the orange area. VI varied from 3.0 to $50.0 \mathrm{~m}^{3} \cdot \mathrm{ha}^{-1}$ and BAI from 0.6 to $6.5 \mathrm{~m}^{2} \cdot \mathrm{ha}^{-1}$ across the sites. In addition, the VI and BAI were determined to be related to the initial stand density. When the initial stand density was very low, the stand productivity had been significantly affected, which will be discussed in detail in the section "Implications for sustainable forest management".

\section{Model evaluation and comparison}

The state-space approach used in this study implies that the future state of the system can be predicted if the current state of the driving variables is known (Tewari 


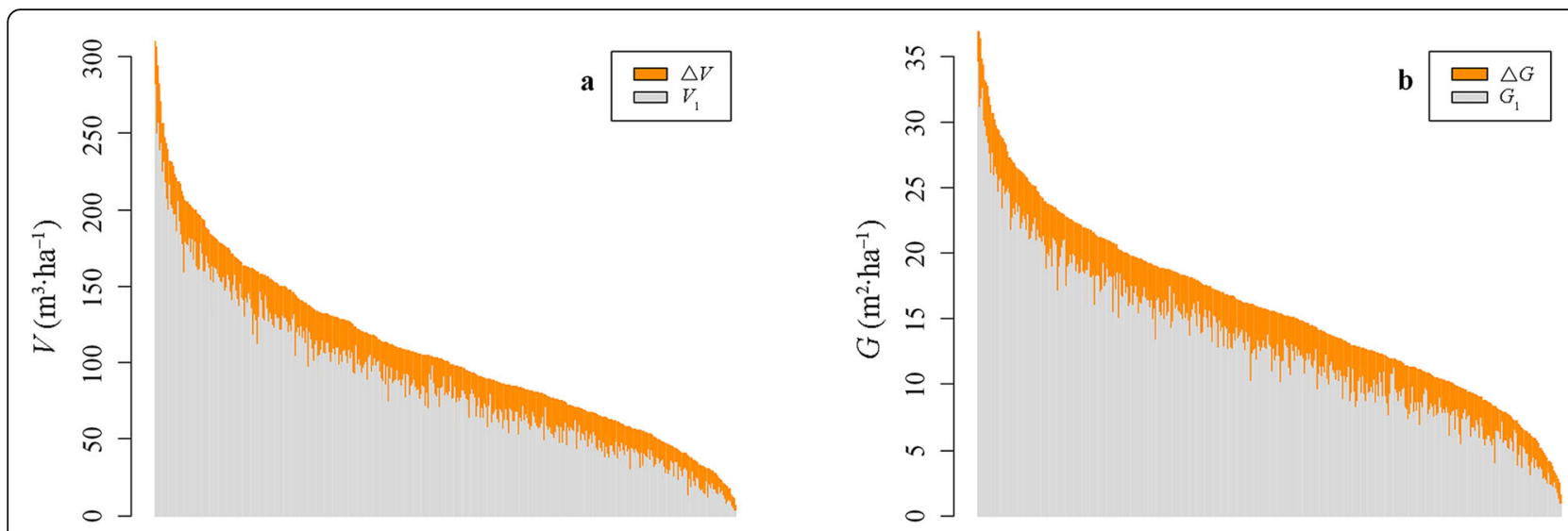

Fig. 3 Stand volume $(V ; \mathbf{a}$, on left) and basal area $(G ; \mathbf{b}$, on right) of each survey plot at the end of the two five-year periods. The grey area represents the amount of accumulation during the initial phase $\left(V_{1}\right.$ or $\left.G_{1}\right)$, and the orange area represents the increase during the two five-year periods $(\Delta V$ or $\Delta G$ )

and Gadow 2005; Álvarez-GonzÁlez et al. 2010; Tewari et al. 2014). In the current study, the applied base model and the extended models had provided adequate performances across the six forest types. The biases of the equations were found to be small, and there were no significant differences in deviation among the four models. However, the $M_{3}$ model performed slightly better, as shown in Table 4. Based on the RMSE results, noticeable differences were observed among the predictive abilities of the models for the different forest types. Also, the RMSE values of the three extended models were significantly reduced, as detailed in Table 5. The third extended model $\left(\mathrm{M}_{3}\right)$, which includes both $H_{\mathrm{dom}}$ and climate factors, had the lowest RMSE for almost all of the forest types, with an average reduction of $13.0 \%$ compared to the base model. The model evaluation results of the MEF were found to be consistent with those based on RMSE. In other words, the three extended systems show adequate performances for all the forest types. $M_{3}$ has the lowest RMSE and the highest model efficiency for the majority of the forest types, as shown in Tables 5 and 6. For the different forest types, the model efficiencies of the two equations had reached averages of 0.968 and 0.961 , respectively. Regarding the different forest types, the RMSE evaluation results show that the prediction accuracy of the model which are based on the different forest types was higher. For example, for the $\mathrm{M}_{3}$ model, the RMSE decreased by $17.1 \%$ for all forest types, by $20.7 \%$ for the mixed broadleafconifer forest, and by $13.9 \%$ for the Mongolian oak forests.

\section{Parameter estimates and model validation}

All of the selected models were convergent and had provided sufficient performances in the different forest types. Most of the estimated parameters of the two equations were significantly different from zero (Table 7). All of the three extended models had improved the predictive abilities of the base model. Therefore, by including either dominant height or climate factors in the base model, the model MEF had increased and the RMSE values had decreased. When the two equations were considered, the inclusion of dominant height $\left(\mathrm{M}_{1}\right)$ provides superior predictive abilities when compared with the model which had included only the climate factors $\left(M_{2}\right)$. The $M_{3}$ model has the lowest RMSE and the highest MEF for all of the forest types and provides the highest accuracy, as well as the best efficiency. Therefore, the combination of dominant height and climatic factors had produced superior results more often than when

Table 4 Bias estimates of the four models for the different forest types

\begin{tabular}{|c|c|c|c|c|c|c|c|c|c|c|}
\hline \multirow[t]{2}{*}{ Bias } & \multirow[t]{2}{*}{$N$} & \multirow[t]{2}{*}{ Trees } & \multicolumn{2}{|c|}{ Base model } & \multicolumn{2}{|c|}{ Base model $+H_{\text {dom }}$} & \multicolumn{2}{|c|}{ Base model + climate } & \multicolumn{2}{|c|}{ Base model $+H_{\text {dom }} \&$ climate } \\
\hline & & & Eq. 1 & Eq. 2 & Eq. 1 & Eq. 2 & Eq. 1 & Eq. 2 & Eq. 1 & Eq. 2 \\
\hline All & 384 & 30,135 & -0.333 & 0.983 & 0.090 & 0.583 & 0.550 & 0.910 & -0.043 & 0.556 \\
\hline Broad-leaved mixed forest & 192 & 15,284 & -0.441 & 0.717 & -0.264 & 0.479 & 0.263 & 0.678 & -0.214 & 0.464 \\
\hline Mixed broadleaf-conifer forest & 30 & 2748 & -1.218 & 0.932 & -0.668 & 0.601 & 2.764 & 0.652 & 0.735 & 0.566 \\
\hline Mongolian oak forest & 92 & 7097 & -0.097 & 1.104 & 0.004 & 0.433 & -0.845 & 0.880 & -0.242 & 0.404 \\
\hline Larch forest & 37 & 2314 & -0.280 & 0.418 & -0.245 & 0.314 & -0.077 & 0.428 & -0.183 & 0.280 \\
\hline Birch forest & 33 & 2692 & -0.217 & 0.446 & -0.171 & 0.446 & 0.188 & 0.430 & -0.114 & 0.431 \\
\hline
\end{tabular}

Bold numbers indicate the lowest bias value of each equation across all of the models for a given forest type 
Table 5 RMSE values for the four models of the different forest types

\begin{tabular}{|c|c|c|c|c|c|c|c|c|c|c|}
\hline \multirow[t]{2}{*}{ Bias } & \multirow[t]{2}{*}{$N$} & \multirow[t]{2}{*}{ Trees } & \multicolumn{2}{|c|}{ Base Model } & \multicolumn{2}{|c|}{ Base Model $+H_{\text {dom }}$} & \multicolumn{2}{|c|}{ Base Model + Climate } & \multicolumn{2}{|c|}{ Base Model $+H_{\text {dom }} \&$ Climate } \\
\hline & & & Eq. 1 & Eq. 2 & Eq. 1 & Eq. 2 & Eq. 1 & Eq. 2 & Eq. 1 & Eq. 2 \\
\hline All & 384 & 30,135 & 12.761 & 1.651 & 10.572 & 1.426 & 12.837 & 1.572 & 10.556 & 1.373 \\
\hline Broad-leaved mixed forest & 192 & 15,284 & 10.652 & 1.382 & 9.950 & 1.198 & 10.598 & 1.351 & 9.941 & 1.191 \\
\hline Mixed broadleaf-conifer forest & 30 & 2748 & 17.639 & 1.511 & 17.424 & 1.451 & 16.956 & 1.498 & 11.572 & 1.406 \\
\hline Mongolian oak forest & 92 & 7097 & 7.626 & 1.763 & 7.617 & 1.296 & 7.790 & 1.702 & 7.657 & 1.265 \\
\hline Larch forest & 37 & 2314 & 5.524 & 0.884 & 5.319 & 0.898 & 5.427 & 0.862 & 5.287 & 0.850 \\
\hline Birch forest & 33 & 2692 & 4.928 & 1.043 & 3.688 & 1.065 & 4.996 & 1.042 & 3.669 & 1.061 \\
\hline
\end{tabular}

Bold numbers indicate the lowest RMSE value of each equation across all the models for a given forest type

each factor had been added individually. In the current study, based on the aforementioned results, the prediction and simulation abilities of the $\mathrm{M}_{3}$ model showed the best performance results when compared with the three other models. Therefore, $\mathrm{M}_{3}$ was selected as the common model for the entire study region.

The experimental testing of the model with new and independent data provided an overall check of the entire model construction process. During the testing of the selected model, all survey plots, broad-leaved mixed forest and Mongolian oak forest were validated with independent data. The predicted stand volume and basal area results versus the observed stand volume and basal area results for the remaining $30 \%$ of the samples are displayed in Fig. 4. Additional file 3 shows the sensitivity analysis of the selected model. The use of the selected models and the coefficients listed in Table 7 had increased the precision of the estimates for the different forest types of northeastern China.

\section{Discussion}

\section{Factors affecting growth model performance}

Understanding the dynamics of forest development is important for calculating sustainable forest use and for evaluating alternative forest management strategies. Our study is a first attempt to estimate such dynamics for a large, diverse and important natural forest region where forest production models are not yet available. Compared with even-aged forest growth models, which have been extensively studied, natural forest stand growth models are more challenging (Burkhart and Tomé 2012). Previous studies have shown certain relationships between site conditions and dominant height of uneven-aged forests (Huang and Titus 1993). Dominant height alone does not fully express all of the required environmental information (Carmean 1975; Pokharel and Dech 2011; Weiskittel et al. 2011), but it is a useful first alternative. The inclusion of dominant height in the base model was found to increase the model MEF and reduce the average RMSE value by $8.9 \%$, as detailed in Tables 5 and 6 . These findings are consistent with the results of numerous previous studies (Gadow and Hui 1999; Weiskittel et al. 2011; Chave et al. 2014; Mensah et al. 2017).

Considering the extensive and widely distributed forests of northeastern China, with varying temperature and precipitation levels, each geographical location will affect forest productivity and ecosystem functions. Further studies are needed extend the applicability of this first model, especially since evidence regarding climate change impacts on forest productivity has been expanding continuously in the recent past, and some of the changes in growth have already been observed (SánchezSalguero et al. 2012; Ruiz-Benito et al. 2014; Spathelf et al. 2014). In order to investigate whether climate factors can replace dominant height, climate variables alone were added to the base model $\left(M_{0}\right)$ in the form of $M_{2}$. However, it was found that there was no significant improvement when compared to $\mathrm{M}_{0}$. It was found that for the majority of the forest types, the results of the $M_{2}$ model were even less efficient than those of $\mathrm{M}_{1}$ (Tables 5

Table 6 MEF values for the four models of the different forest types

\begin{tabular}{|c|c|c|c|c|c|c|c|c|c|c|}
\hline \multirow[t]{2}{*}{ MEF } & \multirow[t]{2}{*}{$N$} & \multirow[t]{2}{*}{ Trees } & \multicolumn{2}{|c|}{ Base model } & \multicolumn{2}{|c|}{ Base model $+H_{\text {dom }}$} & \multicolumn{2}{|c|}{ Base model + climate } & \multicolumn{2}{|c|}{ Base model $+H_{\text {dom }} \&$ climate } \\
\hline & & & Eq. 1 & Eq. 2 & Eq. 1 & Eq. 2 & Eq. 1 & Eq. 2 & Eq. 1 & Eq. 2 \\
\hline$\overline{A l l}$ & 384 & 30,135 & 0.938 & 0.938 & 0.957 & 0.954 & 0.937 & 0.944 & 0.957 & 0.957 \\
\hline Broad-leaved mixed forest & 192 & 15,284 & 0.945 & 0.948 & 0.952 & 0.961 & 0.945 & 0.950 & 0.952 & 0.961 \\
\hline Mixed broadleaf-conifer forest & 30 & 2748 & 0.961 & 0.959 & 0.968 & 0.962 & 0.929 & 0.959 & 0.967 & 0.964 \\
\hline Mongolian oak forest & 92 & 7097 & 0.966 & 0.914 & 0.966 & 0.953 & 0.964 & 0.919 & 0.966 & 0.956 \\
\hline Larch forest & 37 & 2314 & 0.989 & 0.980 & 0.989 & 0.979 & 0.989 & 0.981 & 0.990 & 0.981 \\
\hline Birch forest & 33 & 2692 & 0.963 & 0.948 & 0.979 & 0.945 & 0.962 & 0.948 & 0.979 & 0.946 \\
\hline
\end{tabular}

Bold numbers indicate the highest MEF value of each equation across all of the models for a given forest type 
Table 7 Estimated parameters for the selected growth model $\left(M_{3}\right)$ for each forest type

\begin{tabular}{|c|c|c|c|c|c|c|}
\hline Forest type & All & Broad-leaved mixed forest & Mixed broadleaf-conifer forest & Mongolian oak forest & Larch forest & Birch forest \\
\hline$N$ & 384 & 192 & 30 & 92 & 37 & 33 \\
\hline Trees & 30,135 & 15,284 & 2748 & 7097 & 2314 & 2692 \\
\hline \multicolumn{7}{|l|}{ Eq. 1} \\
\hline$a_{0}$ & $1.3957^{* * *}$ & $1.4079^{* * *}$ & $1.7628^{* * *}$ & $1.3226^{* * *}$ & $1.9215^{* * *}$ & $1.5099^{* * *}$ \\
\hline$a_{1}$ & $0.0151^{* * *}$ & $0.0120^{* * *}$ & $0.0100^{* *}$ & $-0.0038^{\text {ns }}$ & $0.0019^{*}$ & $0.0170^{* * *}$ \\
\hline$a_{2}$ & $-2.0886^{* * *}$ & $-2.2830^{* * *}$ & $-4.1406^{* * *}$ & $-0.7157^{*}$ & $-1.247^{* *}$ & $-1.7083^{*}$ \\
\hline$a_{3}$ & $1.1049^{* * *}$ & $1.1180^{* * *}$ & $1.0500^{* * *}$ & $1.2122^{* * *}$ & $1.0747^{* * *}$ & $1.0173^{* * *}$ \\
\hline \multicolumn{7}{|l|}{ Eq. 2} \\
\hline$b_{0}$ & $1.1418^{* * *}$ & $3.0958^{* * *}$ & $6.1632^{* * *}$ & $0.5858^{\mathrm{ns}}$ & $-0.9892^{\mathrm{ns}}$ & $3.8268^{*}$ \\
\hline$b_{1}$ & $0.0837^{* * *}$ & $0.0820^{* * *}$ & $0.0741^{* * *}$ & $0.1261^{* * *}$ & $0.0410^{* * *}$ & $-0.0250^{\text {ns }}$ \\
\hline$b_{2}$ & $0.0168^{\mathrm{ns}}$ & $-0.0377^{*}$ & $-0.1250^{* *}$ & $-0.0010^{\mathrm{ns}}$ & $0.0960^{*}$ & $-0.0356^{\mathrm{ns}}$ \\
\hline$b_{3}$ & $0.0018^{* * *}$ & $0.0001^{\mathrm{ns}}$ & $-0.0022^{* *}$ & $0.0025^{* * *}$ & $0.0069^{* *}$ & $0.0022^{\text {ns }}$ \\
\hline
\end{tabular}

${ }^{*}$ indicates a significance at the $p<0.05$ level; ${ }^{* *}$ indicates a significance at the $p<0.01$ level; ${ }^{* * *}$ indicates a significance at the $p<0.001$ level; and ns indicates no significance was observed

and 6). The evaluation indicates that none of the dominant height and climate factors were individually sufficient to fully express the contributions of environmental factors to forest production.

Lei et al. (2016) have shown that a traditional growth and yield model has the potential to be modified to function as a climate sensitive model by including climate factors. As expected, the third extended model $\left(\mathrm{M}_{3}\right)$, which includes both dominant height and climate factors, produced results that are superior to those of a traditional growth model (see similar results by Rustad et al. 2012; Ratcliffe et al. 2016; Morin et al. 2018). According to the results, the productivity of stands increased with increasing temperature and precipitation for all forests combined (Table 7). This is logical because adequate precipitation provides sufficient moisture for tree growth. In addition, summers with higher temperatures can increase cambium activity and contribute to the accumulation of photosynthates, which is vital for latewood cell-wall thickening (Rossi et al. 2006). But different results were found in the different forest types. The Birch forest type has the same trend as all forests combined. For the Broad-leaved mixed forest, Mongolian oak forest and Birch forest, temperature had a negative effect on forest productivity. Studies on the temperature response of photosynthetic carbon uptake indicate the existence of an optimum temperature for photosynthesis. Photosynthesis increases with increasing temperature until it reaches an optimum, beyond which rates decrease. The decrease is related to stomatal closure and increased rates of respiration (Lin et al. 2012; Slot and Winter 2017). In addition, the relationship between photosynthesis and temperature may be affected by precipitation. Excessive rainfall is usually coupled with increased cloudiness and reduced solar radiation at the forest canopy below photosynthetic light saturation
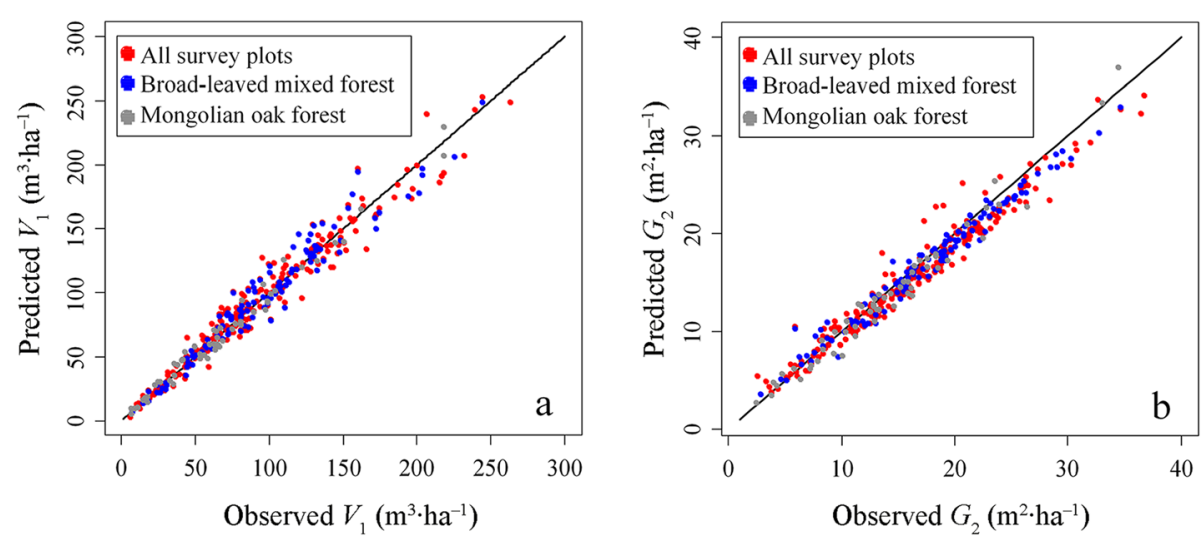

Fig. 4 Predicted versus observed stand volume ( $\mathbf{a}$, on left) and basal area (b, on right) for the three forest types. The colors represent the different forest types; $G_{2}$ is the basal areas of the initial phases of the two five-year periods; and $V_{1}$ is the stand volumes of the initial phases of the two five-year periods 
(Slot and Winter 2017). For the mixed broadleaf-conifer forest, stand productivity is negatively correlated with temperature and precipitation. We have no straight forward explanation for this result, either because of the complexity of the species composition or due to the limitation of the number of samples. Higher photosynthesis and productivity require balanced hydrothermal conditions, which may have different effects of climate variables in the different forest types. This study shows that our selected model has better predictive performance in uneven-aged natural forests than the traditional growth modeling approaches which did not include climatic factors. In future research, the current network of temporary plots will be gradually replaced by a permanent observational network, which will improve essential estimates of forest dynamics, including ingrowth, mortality and response to disturbances.

\section{Implications for sustainable forest management}

The practical problem of sustainable forest management in China's northeastern region is that not enough information is currently available regarding the changes in volume and basal area growth over time in the different forest types of the region. This has been found to severely limit the successful development of sustainable forest management strategies. In our study, the third extended model including both dominant height and climate factors showed superior performance. Future forest management strategies should be flexibly formulated according to the climate differences in a region in order to sustain forest ecosystems more effectively (Lindner et al. 2014).

In addition, it appears that there is no general answer to the question whether the density-production relation is asymptotic or whether there is a stand density that results in maximum production (Pretzsch 2005). Is it possible to increase volume production of a very dense forest by thinning or is production at a maximum under self-thinning conditions? Our observations, presented in Additional file 4 for six forest types, do not provide a straightforward answer. The only conclusion that can be made is that, at low basal areas, there is a steep rise in production with increasing density.

Our observations do not show a clear evidence of transgressive growth caused by thinning, such as found by Pretzsch (2005). One could speculate that there may be a distinct unimodal frontier, with maximum production at about $25 \mathrm{~m}^{2} \cdot \mathrm{ha}^{-1}$, but our data do not allow a clear and consistent interpretation, which is to be expected in forests with a variety of species mixtures and site conditions. This result is consistent with the finding in an afromontane forest (Gadow et al. 2016). The general assumption is that forest production is not asymptotic and will eventually decrease as density reaches very high levels
(Vanclay and Henry 1988; Corral Rivas et al. 2016). However, we cannot confirm or reject this assumption because there is a lack of very high densities in our datasets. Pretzsch (2005) found that the growth of Picea abies reacts most positively to thinning under poor site conditions while increment is reduced on favorable sites. Recent research shows that the density effect on growth depends on the specific species mixtures and site variables (Oliver and Larson 1996; Corral Rivas et al. 2016). The ability to quantify such effects remains to be an important topic for future studies.

\section{Conclusions}

Based on a large set of 0.1 ha forest plots, this study presents a new scientific basis for estimating the productive potential of the natural or near-natural forest resources of northeastern China. Model performance was improved by including regional climate variables. The new system of equations, extensively tested using independent data sets, may be used to estimate production of six different forest types under different climate scenarios. In addition, the relatively simple form and convenient use of the new forest model makes it suitable as a first scientific basis for decision support. This will enable forest managers to calculate sustainable use and develop improved management strategies for different local conditions. The results, although preliminary, can already contribute to improving resource planning and management in this important forest region of China.

\section{Supplementary information}

Supplementary information accompanies this paper at https://doi.org/10. 1186/s40663-019-0204-0.

Additional file 1. List of the volume equations of different species in the four provinces.

Additional file 2. The volume proportions of the different tree species in each plot.

Additional file 3. Summary statistics of the main stand variables for each forest type and sensitivity analysis of the selected model.

Additional file 4: Figure S1. Density-production relations for six forest types.

\footnotetext{
Abbreviations

3SLS: Three-stage least squares technique; A: Average age of dominant trees; BAl: Basal area increments; $\mathrm{DBH}$ : Breast height diameter; $\mathrm{DBH}_{07}$ : Diameters at breast height in 2007; $\mathrm{DBH}_{12}$ : Diameters at breast height in 2012; E: Bias; G: Stand basal area; GSP: The growth season precipitation; GST: The growth season temperatures; $\mathrm{H}_{\text {dom: }}$ : Dominant height; $\mathrm{id}_{1}$ : Diameter increment in 2007-2012; id 2: Diameter increment in 2012-2017; IDW: Inverse Distance Weighted; $\mathrm{M}_{0}$ : Basic stand growth model; $\mathrm{M}_{1}$ : The first extended model; $\mathrm{M}_{2}$ : The second extended model; $\mathrm{M}_{3}$ : The third extended model; MEF: Model efficiency; N: Number of trees per hectare; RMSE: Root mean square error; SI: Site index; SUR: Seemingly unrelated regression; V: Stand volume; VI: Stand volume increments
} 


\section{Acknowledgements}

Not applicable.

\section{Authors' contributions}

ZW and JW analyzed the data and led the writing of the manuscript. JW and ZZ designed the experiments and collected the data. All authors read and approved the final manuscript.

\section{Funding}

This research is supported by the Key Project of National Key Research and Development Plan (No. 2017YFC0504104) and the Program of National Natural Science Foundation of China (No. 31670643).

\section{Availability of data and materials}

The datasets used during the current study are available from the corresponding author on reasonable request.

\section{Ethics approval and consent to participate}

Not applicable.

\section{Consent for publication}

Not applicable.

\section{Competing interests}

The authors declare that they have no competing interests.

\section{Author details}

${ }^{1}$ Research Center of Forest Management Engineering of State Forestry and Grassland Administration, Beijing Forestry University, Beijing 100083, China.

${ }^{2}$ Jilin Provincial Academy of Forestry Sciences, Changchun 130031, China.

\section{Received: 31 July 2019 Accepted: 29 September 2019}

Published online: 12 October 2019

\section{References}

Álvarez-González JG, Zingg A, Gadow KV (2010) Estimating growth in beech forests: a study based on long term experiments in Switzerland. Ann Forest Sci 67:307

Borders BE (1989) Systems of equations in forest stand modelling. For Sci 35:548556

Buckman RE (1962) Growth and yield of red pine in Minnesota. US Dept. of Agriculture, Washington

Burkhart HE (2008) Modelling growth and yield for intensively managed forests. J Forest Environ Sci 24:119-126

Burkhart HE, Tomé M (2012) Modeling forest trees and stands. Springer Science \& Business Media, New York

Carmean WH (1975) Forest site quality evaluation in the United States. Adv Agron 27:209-269

Chave J, Réjou-Méchain M, Búrquez A, Chidumayo E, Colgan MS, Delitti WBC, Duque A, Eid T, Fearnside PM, Goodman RC, Henry M, Martínez-Yrízar A, Mugasha WA, Muller-Landau HC, Mencuccini M, Nelson BW, Ngomanda A, Nogueira EM, Ortiz-Malavassi E, Pélissier R, Ploton P, Ryan CM, Saldarriaga JG, Vieilledent G (2014) Improved allometric models to estimate the aboveground biomass of tropical trees. Glob Chang Biol 20:3177-3190

Choi J, An H (2016) A forest growth model for the natural broadleaved forests in northeastern Korea. Forests 7:288

Clutter JL (1963) Compatible growth and yield models for loblolly pine. For Sci 9: 354-371

Clutter JL, Fortson JC, Pienaar LV, Brister GH, Bailey RL (1983) Timber management: a quantitative approach. Wiley, New York

Corral-Rivas JJ, Torres-Rojo JM, Lujan-Soto JE, Nava-Miranda MG, Aguirre-Calderon OA, Gadow KV (2016) Density and production in the natural forests of Durango/Mexico. Allgemeine Forst und Jagdzeitung 187:93-103

Da Cunha TA, Finger CAG, Hasenauer H (2016) Tree basal area increment models for Cedrela, Amburana, Copaifera and Swietenia growing in the Amazon rain forests. Forest Ecol Manag 365:174-183

Gadow KV, Hui GY (1999) Modelling stand development. Kluwer Academic Publishers, Dodrecht

Gadow KV, Zhang G, Durrheim G, Drew D, Seydack A (2016) Diversity and production in an afromontane forest. Forest Ecosyst 3:15. https://doi.org/10. 1186/s40663-016-0074-7
García O, Burkhart HE, Amateis RL (2011) A biologically-consistent stand growth model for loblolly pine in the Piedmont physiographic region, USA. Forest Ecol Manag 262:2035-2041

Gül AU, Misir M, Misir N, Yavuz H (2005) Calculation of uneven-aged stand structures with the negative exponential diameter distribution and Sterba's modified competition density rule. Forest Ecol Manag 214:212-220

Guo YR, Wu BG, Liu Y, Ju HB, Wang CQ (2012) Research progress of site quality evaluation. World Forest Res 25:47-52

Huang S, Titus SJ (1993) An index of site productivity for uneven-aged or mixedspecies stands. Can J For Res 23:558-562

Lei X, Yu L, Hong L (2016) Climate-sensitive integrated stand growth model (CSISGM) of Changbai larch (Larix olgensis) plantations. Forest Ecol Manag 376: $265-275$

Lin YS, Medlyn BE, Ellsworth DS (2012) Temperature responses of leaf net photosynthesis: the role of component processes. Tree Physiol 32:219-231

Lindner M, Fitzgerald JB, Zimmermann NE, Reyer C, Delzon S, der Maaten EV, Schelhaas MJ, Lasch P, Eggers J, der Maaten-Theunissen MV, Suckow F, Psomas A, Poulter B, Hanewinkel M (2014) Climate change and European forests: what do we know, what are the uncertainties, and what are the implications for forest management? J Environ Manag 146:69-83

Mensah S, Veldtman R, Seifert T (2017) Allometric models for height and aboveground biomass of dominant tree species in south African Mistbelt forests. South Forests 79:19-30

Monserud RA, Sterba H (1996) A basal area increment model for individual trees growing in even-and uneven-aged forest stands in Austria. Forest Ecol Manag 80:57-80

Mora J, del Rio M, Bravo-Oviedo A (2012) Dynamic growth and yield model for black pine stands in Spain. Forest Syst 21:439-445

Morin X, Fahse L, Jactel H, Scherer-Lorenzen M, García-Valdés R, Bugmann H (2018) Long-term response of forest productivity to climate change is mostly driven by change in tree species composition. Sci Rep 8:5627

Moser JW, Hall OF (1969) Deriving growth and yield functions for uneven-aged forest stands. For Sci 15:183-188

Murphy PA, Farrar RM (1982) Interim models for basal area and volume projection of uneven-aged loblolly-shortleaf pine stands. South J Appl Forest 6:115-119

Oliver CD, Larson BC (1996) Forest stand dynamics. Wiley, New York, p 520

Palahí M, Pukkala T, Kasimiadis D, Poirazidis K, Papageorgiou AC (2008) Modelling site quality and individual-tree growth in pure and mixed Pinus brutia stands in north-east Greece. Ann Forest Sci 65:1

Peng C (2000) Growth and yield models for uneven-aged stands: past, present and future. Forest Ecol Manag 132:259-279

Pinto PE, Gégout JC, Hervé JC, Dhôte JF (2008) Respective importance of ecological conditions and stand composition on Abies alba Mill. dominant height growth. Forest Ecol Manag 255:619-629

Pokharel B, Dech JP (2011) An ecological land classification approach to modeling the production of forest biomass. Forest Chron 87:23-32

Pretzsch H (2005) Stand density and growth of Norway spruce (Picea abies (L.) Karst.) and European beech (Fagus sylvatica L.): evidence from long-term experimental plots. Eur J Forest Res 124:193-205

Ratcliffe S, Liebergesell M, Ruiz-Benito P, González JM, Muñoz-Castañeda JM, Kändler G, Lehtonen A, Dahlgren J, Kattge J, Peñuelas J, Zavala MA, Wirth C (2016) Modes of functional biodiversity control on tree productivity across the European continent. Glob Ecol Biogeogr 25:251-262

Ren RJ, Kang XG, Yang H (2008) Review on growth model of individual-tree in nature forest. J Northwest Forest Univ 6:50

Rossi S, Deslauriers A, Anfodillo T, Morin H, Saracino A, Motta R, Borghetti M (2006) Conifers in cold environments synchronize maximum growth rate of tree-ring formation with day length. New Phytol 170:301-310

Ruiz-Benito P, Madrigal-Gonzalez J, Ratcliffe S, Ratcliffe S, Coomes DA, Kändler G, Lehtonen A, Wirth C, Zavala MA (2014) Stand structure and recent climate change constrain stand basal area change in European forests: a comparison across boreal, temperate, and Mediterranean biomes. Ecosystems 17:14391454

Rustad L, Campbell J, Dukes JS, Huntington T, Fallon K (2012) Changing climate, changing forests: the impacts of climate change on forests of the northeastern United States and eastern Canada. Gen. Tech. Rep. NRS-99. US Department of Agriculture, Forest Service, Northern Research Station, Newtown Square

Sánchez-Salguero R, Navarro-Cerrillo RM, Camarero JJ, Fernández-Cancio Á (2012) Selective drought-induced decline of pine species in southeastern Spain Clim Chang 113:767-785 
Schumacher FX (1939) A new growth curve and its application to timber yield studies. J Forest 37(10):819-820

Skovsgaard JP, Vanclay JK (2008) Forest site productivity: a review of the evolution of dendrometric concepts for even-aged stands. Forestry 81:13-31

Slot M, Winter K (2017) In situ temperature response of photosynthesis of 42 tree and liana species in the canopy of two Panamanian lowland tropical forests with contrasting rainfall regimes. New Phytol 214:1103-1117

Spathelf P, Van Der Maaten E, Van Der Maaten-Theunissen M, Campioli M, Dobrowolska D (2014) Climate change impacts in European forests: the expert views of local observers. Ann Forest Sci 71:131-137

Sullivan AD, Clutter JL (1972) A simultaneous growth and yield model for loblolly pine. For Sci 18:76-86

Temesgen H, Zhang C, Zhao X (2014) Modelling tree height-diameter relationships in multi-species and multi-layered forests: a large observational study from Northeast China. Forest Ecol Manag 316:78-89

Tewari VP, Álvarez-González JG, Gadow KV (2014) Dynamic base-age invariant site index models for Tectona grandis in peninsular India. South Forest 76(1):21-27

Tewari VP, Gadow KV (2005) Basal area growth of even-aged Azadirachta indica stands in Gujarat State, India. J Trop Forest Sci 17(3):386-398

Vanclay JK, Henry NB (1988) Assessing site productivity of indigenous cypress pine forest in southern Queensland. Commonw Forest Rev 67(1):53-64

Weiskittel AR, Crookston NL, Radtke PJ (2011) Linking climate, gross primary productivity, and site index across forests of the western United States. Can J For Res 41:1710-1721

Zang H (2016) Regional-scale climate-sensitive stand growth models for larch plantations. Doctoral Dissertation, Chinese Academy of Forestry

Zellner A (1962) An efficient method of estimating seemingly unrelated regressions and tests for aggregation bias. J Am Stat Assoc 57:348-368

Zellner A, Theil H (1992) "Three-stage least squares: simultaneous estimation of simultaneous equations." Henri Theil's Contributions to Economics and Econometrics. Springer, Dordrecht, pp 147-178

Zeng WS, Duo HR, Lei XD, Chen XY, Wang XJ, Pu Y, Zou WT (2017) Individual tree biomass equations and growth models sensitive to climate variables for Larix spp. in China. Eur J Forest Res 136:233-249

Zhao LL (2011) Growth models of natural forests in Xiao Xing'an mountains. Northeast Forestry University, Master Dissertation

Zheng YJ, Xiao XM, Guo ZW, Howard TE (2001) A county-level analysis of the spatial distribution of forest resources in China. J Forest Plan 7:69-78

\section{Submit your manuscript to a SpringerOpen ${ }^{\circ}$ journal and benefit from:}

- Convenient online submission

- Rigorous peer review

- Open access: articles freely available online

- High visibility within the field

- Retaining the copyright to your article

Submit your next manuscript at $\boldsymbol{\nabla}$ springeropen.com 